\title{
Physics Comprehensive and Contextual Teaching Material (PhysCCTM) untuk Meningkatkan Higher Order Thinking Skill (HOTS) Siswa SMA
}

\author{
Nugroho Prasetya Adi, Suparno, Mudilarto, Edi Istiyono, Rattiwizal Alpin Y, \\ Muhammad Zaini, Syayid Qosim M.J.A \\ Universitas Negeri Yogyakarta \\ nugrohoprasetyaadi@gmail.com
}

\begin{abstract}
This study aimed to: (1) produce Physics Comprehensive and Contextual Teaching Material (PhysCCTM) which was reasonably for physics learning in SMA, and (2) examine the effectiveness of Physics Comprehensive and Contextual Teaching Material (PhysCCTM) to increase students Higher Order Thinking Skill (HOTS). This research used R\&D methods with 4D models consisting of (1) Define, (2) Design, (3) Developt, and (4) Disseminate. The resulted product is PhysCCTM. The data were colleted by using an evaluation sheet of product, and test of HOTS. The data were analyzed using Aiken $V$ to assess the product quality, and $N$-Gain analysis. The result of this research produced teaching material PhysCCTM which: (1) was reasonably to increase students HOTS with very good category based on expert, teachers, and good category based the response of students, and (2) effective to increase students HOTS significantly by effectivity on Partial Eta Squared in Multivariate Test with the value is $90,4 \%$.
\end{abstract}

Keywords: Physics Comprehensive and Contextual Teaching Material (PhysCCTM), Higher Order Thinking Skill (HOTS)

\begin{abstract}
Abstrak: Penelitian ini bertujuan: (1) untuk menghasilkan Physics Comprehensive and Contextual Teaching Material (PhysCCTM) yang layak untuk pembelajaran fisika di SMA, dan (2) menguji efektivitas Physics Comprehensive and Contextual Teaching Material (PhysCCTM) dalam meningkatkan Higher Order Thingking Skill (HOTS) siswa SMA. Penelitian pengembangan ini menggunakan metode R\&D dengan model 4D yang meliputi tahap (1) Define, (2) Design, (3) Develop, dan (4) Disseminate. Produk yang dihasilkan adalah PhysCCTM. Instrumen pengumpulan data yang digunakan adalah lembar penilaian perangkat pembelajaran, dan lembar penilaian HOTS. Teknik analisis data yang digunakan adalah Aiken $\mathrm{V}$ untuk melihat kualitas produk dan analisis General Linier Model (GLM). Hasil penelitian menunjukkan bahwa telah dihasilkan produk PhysCCTM yang: (1) layak digunakan untuk meningkatkan HOTS dengan kategori sangat baik berdasarkan penilaian ahli dan guru, serta kategori baik berdasarkan respon siswa, dan (2) efektif untuk meningkatkan HOTS siswa secara signifikan berdasarkan efektivitas pada Partial Eta Square di Multivariate Test dengan nilai $90,4 \%$.
\end{abstract}

Kata kunci: Physics Comprehensive and Contextual Teaching Material (PhysCCTM), Higher Order Thinking Skill (HOTS)

\section{PENDAHULUAN}

Pendidikan di Indonesia saat ini sedang dihadapkan dalam suatu kondisi kritis dengan dihadapkan pada diberlakukannya pasar bebas Masyarakat Ekonomi Asean (MEA) yang telah diselenggarakan akhir tahun 2015. Kondisi kritis pendidikan nasional ini perlu mendapatkan penanganan secepatnya agar mampu menghasilkan sumber daya manusia (SDM) yang mampu bersaing dengan negara - negara di ASEAN atau bahkan seluruh negara di dunia. Hasil Survei dari Programme for International Student Assessment (PISA, 2015) pada siswa usia 15 tahun dalam bidang matematika, IPA dan Bahasa menempatkan Indonesia pada posisi 62 dari 70 peserta. Dijelaskan lagi, bahwa 75,7\% kemampuan siswa Indonesia masih 
tergolong dalam level 2 atau masih tergolong dalam kemampuan tingkat rendah. Hasil survei dari IEA's Trends in International Mathematics and Science Study (TIMSS, 2011) menjelaskan bahwa prestasi sains siswa Indonesia berada pada level yang rendah. Indonesia mendapatkan skor skala rata - rata 406 untuk prestasi sains, sehingga masuk ke dalam kategori level rendah. Oleh karena itu diperlukan sebuah upaya untuk melakukan perubahan dan perbaikan guna meningkatkan mutu pendidikan di Indonesia, salah satunya melalui mata pelajaran fisika.

Fisika adalah salah satu mata pelajaran wajib yang harus dipelajari oleh siswa di sekolah, karena berhubungan erat dengan lingkungan kehidupan dan merupakan salah satu dasar dari perkembangan teknologi. Walaupun fisika sangat berhubungan erat dengan lingkungan kehidupan manusia, namun masih banyak siswa yang beranggapan bahwa fisika adalah salah satu mata pelajaran yang sulit jika dipelajari di bangku sekolah. Hasil survei lapangan menunjukan bahwa masih banyak siswa yang kurang semangat dalam belajar fisika di kelas, dapat dilihat dari kurangnya perhatian siswa terhadap guru ketika menjelaskan materi pelajaran. Hasil survei juga menunjukkan di beberapa sekolah, siswa tidak mempunyai bahan ajar yang menjadi pegangan untuk belajar di rumah. Bahan ajar hanya bisa dipinjam di perpustakaan dikarenakan terbatas nya jumlah bahan ajar yang dimiliki oleh pihak sekolah. Hal ini mengakibatkan turunnya motivasi siswa untuk belajar dan turunnya minat siswa untuk mempelajari fisika sehingga berimbas pada hasil belajar siswa terhadap mata pelajaran fisika.

Hasil Ujian Nasional tingkat SMA dari tahun pelajaran 2011/2012 - 2013/2014 menunjukkan penurunan nilai pada 4 kompetensi yang diujikan pada materi fisika, yaitu kemagnetan dan elektromagnetik, listrik statik dan listrik dinamik, fluida statik dan fluida dinamik, fisika modern (Litbang Kemdikbud, 2014). Ini menandakan bahwa kebanyakan siswa SMA masih berada pada kemampuan berfikir tingkat rendah atau hanya mampu mengerjakan soal - soal dimana mereka telah mendapatkan informasi yang lengkap dan langsung bisa dijawab tanpa harus siswa tersebut melakukan kesimpulan layaknya persoalan yang menuntut kemampuan berfikir tingkat tinggi (HOTS).

Brookhart (2010) menjelaskan HOTS sebagai sebuah kemampuan yang dimiliki oleh siswa untuk menerapkan pengetahuan dan keterampilan yang mereka akan kembangkan selama mengikuti sebuah proses pembelajaran pada konsep yang belum dipikirkan sebelumnya, akan tetapi konsep tersebut telah diajarkan sebelumnya. Ramos et al, (2013) menjelaskan bahwa Higher Order Thinking Skill (HOTS) terdiri dari kemampuan menganalisis, mengevaluasi, mensintesis, serta menciptakan yang berada pada level 4, 5, dan 6. Kemampuan ini juga sangat berpengaruh kepada siswa terutama pada hasil belajarnya khususnya pada mata pelajaran fisika. Karena dalam fisika siswa dituntut untuk mampu memahami konsep konsep, menganalisa, serta mengevaluasi apa yang dikerjakan. Oleh karena itu, kemampuan berfikir tingkat tinggi siswa hendaknya dikembangkan agar menjadi bekal yang bermanfaat dalam era globalisasi seperti sekarang ini. Limbach \& Waugh (2010) mengungkapkan bahwa untuk mengembangkan HOTS harus memenuhi langkah - langkah pada proses pembelajaran yaitu a) menentukan tujuan dari pembelajaran yang ingin dicapai, b) mengajarkan materi pelajaran melalui bertanya kepada siswa, 3) mempraktikan apa yang dipelajari, 4) menelaah, mempertajam dan meningkatkan pemahaman siswa, 5) memberikan umpan balik kepada siswa dan menilai proses pembelajaran yang telah berlangsung.

Salah satu kompetensi yang harus diterapkan untuk meningkatkan kompetensi dan kualitas sumber daya alam sebagai output dari mata pelajaran fisika adalah dengan menerapkan suatu standar kompetensi, salah satunya adalah KKNI (Kualifikasi Kompetensi Nasional Indonesia). KKNI dirancang untuk meningkatkan kualitas SDM, yang dimana pada setiap levelnya bisa ditempuh dengan berbagai cara yang berbeda, salah satunya adalah dalam 
bidang pendidikan. Untuk kesuksesan pendidikan nasional kedepannya, terkhusus pada mata pelajaran fisika diharapkan agar KKNI bisa diterapkan dalam proses pembelajaran yang berlangsung. Akan tetapi, permasalahan yang terjadi dalam upaya melaksanakan KKNI adalah belum adanya bahan ajar yang mengacu pada KKNI.

Solusi yang akan diberikan pada penelitian ini untuk mengatasi masalah - masalah yang ada adalah dengan memberikan bahan ajar yang mampu meningkatkan kemampuan berfikir tingkat tinggi siswa. Bahan ajar yang dimaksud adalah PhysCCTM (Physics Comprehensive and Contextual Teaching Material) berbantuan android. PhysCCTM merupakan bahan ajar yang dikembangkan berdasarkan konsep - konsep fisika yang berkaitan dengan konten, proses dan aplikasinya secara kontekstual dalam kehidupan sehari - hari yang ditekankan pada aspek kognitif, afektif, serta psikomotorik, yang dikhususkan untuk meningkatkan kemampuan berfikir tingkat tinggi (HOTS) siswa SMA.

\section{METODE PENELITIAN}

\subsection{Jenis Penelitian}

Penelitian ini menggunakan metode penelitian Research and Development (R\&D). Pada penelitian ini dikembangkan bahan ajar Physics Comprehensive and Contextual Teaching Material yang mengacu pada model pengembangan 4D, yang terdiri dari 4 tahapan yaitu: Define, Design, Developt, dan Disseminate.

\subsection{Waktu dan Tempat Penelitian}

Penelitian ini dilaksanakan selama 2 bulan, mulai dari bulan Maret-bulan April 2017 di SMA N 1 Wonosobo dan SMA N 2 Wonosobo.

\subsection{Target/Subjek Penelitian}

Populasi dari penelitian ini adalah semua siswa kelas XI dari SMA N 1 dan SMA N 2 Wonosobo. Sampel dari penelitian ini adalah siswa kelas XI MIPA 4 dan XI MIPA 5 di SMA N 1 dan kelas XI MIPA 4 dan XI MIPA 5 di SMA N 2 Wonosobo, dengan jumlah siswa 67 orang untuk kelas eksperimen dan 61 orang untuk kelas kontrol. Pengambilan sampel pada penelitian ini menggunakan Cluster Sampling (area sampling).

\subsection{Prosedur}

Penelitian ini dilakukan pada dua kelas XI MIPA yang berbeda, dengan 1 kelas menjadi kelas eksperimen dan 1 kelas lainnya menjadi kelas kontrol. Kedua kelas tersebut akan dilakukan pretest dan posttest yang diberikan pada awal dan akhir dari pembelajaran. Pada kelas eksperimen akan diberikan treatment dengan menerapkan penggunaan bahan ajar Physics Comprehensive and Contextual Teaching Material (PhysCCTM). Adapun design dari penelitian ini dapat dilihat pada Tabel 1. Berikut

Tabel 1. Design Penelitian

\begin{tabular}{lccc}
\hline \multicolumn{1}{c}{ Kelas } & Pretest & Perlakuan & Posttest \\
\hline Eksperimen & $\mathrm{O}_{1}$ & $\mathrm{X}_{1}$ & $\mathrm{O}_{2}$ \\
Kontrol & $\mathrm{O}_{1}$ & $\mathrm{X}_{2}$ & $\mathrm{O}_{2}$
\end{tabular}

Adapun teknik pengumpulan data pada penelitian ini adalah sebagai berikut

1) Observasi Langsung

Dilakukan untuk memperoleh data tentang kondisi siswa, kondisi sekolah, dan proses pembelajaran yang berlangsung. 
2) Angket

Angket terdiri dari 3 jenis, yaitu angket validasi bahan ajar PhysCCTM, angket penilaian bahan ajar PhysCCTM dan angket respon siswa terhadap bahan ajar PhysCCTM

3) Tes

Tes digunakan untuk mengetahui peningkatan Higher Order Thinking Skill (HOTS) siswa selama mengikuti proses pembelajaran. Tes yang digunakan adalah pilihan ganda beralasan. Tes diberikan sebanyak dua kali, di awal pembelajaran dan di akhir pembelajaran.

4) Dokumentasi

Dokumentasi berupa hasil dari pretest dan posttest siswa.

\section{TENIK ANALISIS DATA}

\subsection{Analisis Validitas dan Reliabilitas Instrumen Pengumpul Data}

\subsubsection{Validitas Isi Instrumen Pengumpul Data}

Validasi isi ditentukan menggunakan kesepakatan ahli. Kesepakatan ahli bidang studi atau disebut dengan domain yang diukur menentukan tingkatan validitas isi. Untuk mengetahui kesepakatan ahli ini, dapat digunakan indeks validitas, antara lain indeks validitas yang diusulkan oleh Aiken, dengan perumusan nya sebagai berikut:

$$
V=\frac{S}{[m(c-1)]}
$$

\subsubsection{Reliabilitas Instrumen Pengumpul Data}

Reliabilitas mengacu pada kekonsistensian pengukuran, yaitu bagaimana skor tes atau hasil penilaian yang lain tidak berubah (tetap). Reliabilitas dihitung dengan menentukan persentase kesepakatan dari para rater menggunakan persamaan berikut (Borich, 2016:239)

$$
R=\left[1-\frac{A-B}{A+B}\right] \times 100 \%
$$

\subsubsection{Analisis Angket Respon}

Analisis angket respon dilakukan dengan menjumlahkan skor masing-masing aspek yang ada di dalam angket respon siswa. Skor yang didapat pada angket respon dijumlahkan, kemudian dicari rata-rata menggunakan

$$
\bar{X}=\frac{\sum X}{n}
$$

\subsubsection{Analisis Peningkatan HOTS}

Peningkatan HOTS siswa dalam uji coba lapangan dinyatakan dengan nilai Normalized Gain (N-Gain) berdasarkan dari data hasil pretest dan posttest. Hake (1998) menjelaskan bahwa Normalized Gain diperoleh dari rerata posttest dikurangi nilai rerata pretest dan dapat dicari dengan menggunakan persamaan

$$
\langle g\rangle=\frac{\bar{X}_{\text {Posttest }}-\bar{X}_{\text {Pretest }}}{\bar{X}_{\text {max }}-\bar{X}_{\text {Pretest }}}
$$

\subsubsection{Analisis Efektivitas Bahan Ajar PhysCCTM}

Analisis ini dilakukan untuk mengetahui efektivitas bahan ajar PhysCCTM berbantuan android dengan melihat HOTS dan sikap terbuka siswa antara kelas eksperimen dan kelas kontrol sebelum dan sesudah diberikan perlakuan yang berbeda pada tiap kelasnya. Data yang digunakan pada analisis ini adalah data gain (selisih nilai prestest dan posttest). Uji yang 
dilakukan pada analisis ini adalah uji statistik anava. Uji ini bertujuan untuk melihat perbedaan antara dua kelompok percobaan, yang dimana di tiap - tiap kelompok terdiri dari satu variabel terikat, dan akan dilakukan analisis statistik pada variabel terikat tersebut secara bersama - sama.

Sebelum dilakukan uji anava terlebih dahulu harus melakukan beberapa uji asumsi yaitu data tentang variabel terikat pada masing - masing kelas berasal dari populasi yang terdistribusi normal bivariate dan matriks varian/ kovarian dari variabel dependen adalah sama (Stevens, 2009). Uji yang dilakukan pada tahap ini dilakukan dengan bantuan software SPSS 16.0.

\section{HASIL PENELITIAN DAN PEMBAHASAN}

\subsection{Validasi Instrumen Penelitian}

Validasi instrumen dilakukan untuk mengetahui apakah instrumen yang akan digunakan dalam menilai produk yang dihasilkan sudah valid dan reliabel. Tujuan dari validasi ini agar instrumen yang digunakan dapat mengukur apa yang seharusnya diukur. Adapun hasil dari tahap validasi instrumen adalah sebagai berikut:

\subsubsection{Hasil Validasi Intrumen Bahan Ajar, Angket Respon Siswa, dan Lembar Penilaian HOTS}

Instrumen yang telah disusun diberikan kepada ahli/ dosen untuk dinilai sebelum digunakan dalam proses penelitian. Adapun hasil dari validasi intrumen dapat dilihat pada Tabel 2, berikut.

Tabel 2. Hasil Validasi Isi dan Reliabilitas

\begin{tabular}{lccc}
\hline \multicolumn{1}{c}{ Instrumen } & Validity Coefisien $V$ & Intepretasi & Reliabel \\
\hline Lembar Penilaian Bahan Ajar & 1,00 & Valid & Reliabel \\
Lembar Penilaian Respon Siswa & 1,00 & Valid & Reliabel \\
Lembar Penilaian HOTS & 1,00 & Valid & Reliabel \\
\hline
\end{tabular}

\subsubsection{Hasil Validitas Angket Respon Siswa}

Validitas dan reliabilitas dari angket respon dianalisis menggunakan program Quest. Adapun hasil dari validitas dan reliabilitas angket respon siswa dapat dilihat pada Tabel 3 berikut.

Tabel 3. Hasil Validitas Angket Respon Siswa

\begin{tabular}{ccccc}
\hline $\begin{array}{l}\text { Infit } \\
\mathrm{t}\end{array}$ & Intepretasi & Output & Intepretasi & Reliabilitas \\
\hline 1,3 & Cocok & 1,0 & Lolos & \\
0,1 & Cocok & 0,0 & Lolos & \\
0,3 & Cocok & 0,3 & Lolos & \\
$-0,7$ & Cocok & $-0,4$ & Lolos & \\
0,1 & Cocok & 0,0 & Lolos & Reliabel \\
$-0,3$ & Cocok & $-0,3$ & Lolos & \\
$-0,2$ & Cocok & $-0,2$ & Lolos & \\
0,0 & Cocok & 0,3 & Lolos & \\
$-1,0$ & Cocok & $-0,8$ & Lolos & \\
0,4 & Cocok & 0,2 & Lolos & \\
\hline
\end{tabular}




\subsubsection{Hasil Validitas dan Reliabilitas Soal HOTS}

Hasil dari reliabilitas soal HOTS setelah diujicobakan terbatas didapatkan tingkat reliabilitas 0,80 , dapat disimpulkan bahwa setiap butir soal HOTS dapat dikatakan bagus.

Untuk melihat normalitas reliabilitas atau kemampuan siswa ketika diberi soal HOTS dapat menggunakan analisis Graph (Item Information Function) hasilnya dapat dilihat pada Gambar 1 berikut

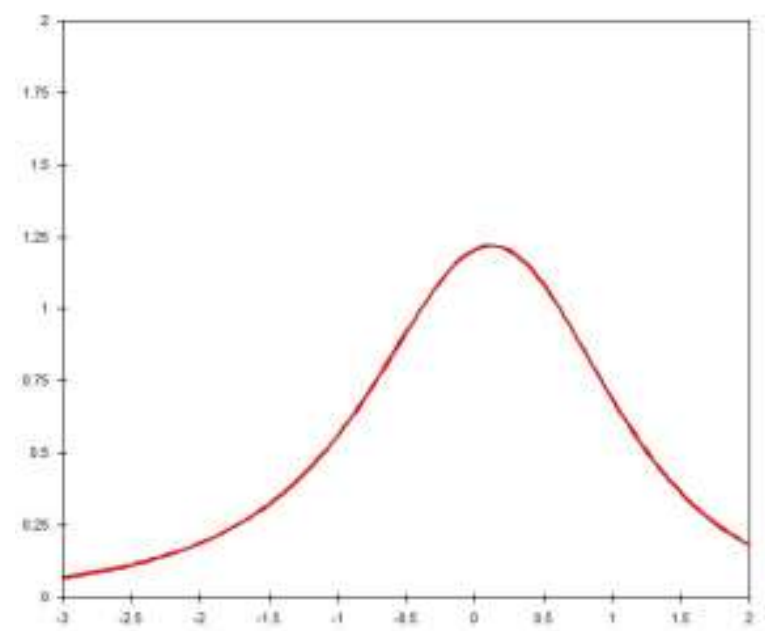

Gambar 1. Grafik Kemampuan HOTS Siswa

Grafik kurva fungsi informasi memperlihatkan bahwa soal yang dikerjakan siswa baik untuk digunakan sebagai ujian formatif karena terlihat dari level abilitas sedang (nilai logitnya $=0$ ) sehingga informasi yang didapatkan sangat tinggi. Hal ini menunjukkan soal HOTS yang dibuat kemudian diberikan kepada siswa menghasilkan informasi yang optimal untuk siswa berkemampuan sedang.

\subsection{Hasil Uji Coba Lapangan}

\subsubsection{Peningkatan HOTS Siswa}

Peningkatan HOTS siswa dapat dilihat dari nilai Gain yang didapatkan siswa setelah melewati pretest dan posttest. Adapun hasil dari peningkatan HOTS siswa dapat dilihat pada Tabel 4 berikut

Tabel 4. Hasil Peningkatan HOTS Siswa

\begin{tabular}{lccc}
\hline \multirow{2}{*}{ Kelas } & \multicolumn{3}{c}{ Rerata Nilai HOTS } \\
& Pretest & Posttest & N-Gain \\
\hline Eksperimen & 44,53 & 75,82 & 0,56 \\
Kontrol & 45,91 & 68,14 & 0,41 \\
\hline
\end{tabular}

Berdasarkan Tabel 4, dapat disimpulkan bahwa peningkatan HOTS berada pada kategori sedang.

\subsubsection{Respon Siswa Terhadap PhysCCTM}

Data respon siswa terhadap PhysCCTM berbantuan android diperoleh melalui angket respon siswa yang telah valid. Hasil rata - rata respon siswa terhadap PhysCCTM ddapat dilihat pada Tabel 5 berikut 
Tabel 5. Hasil Repon Siswa

\begin{tabular}{lcc}
\hline \multicolumn{1}{c}{ Aspek } & $\begin{array}{c}\text { Rerata } \\
\text { Skor }\end{array}$ & Kriteria \\
\hline Tampilan Bahan Ajar PhysCCTM & 3,59 & Baik \\
Kemudahan kata, istilah, dan kalimat untuk dipahami & 3,51 & Baik \\
Kebakuan ejaan & 3,48 & Baik \\
Keterbacaan jenis huruf yang digunakan & 3,44 & Baik \\
Ilustrasi menarik dan menambah banyak pengetahuan & 3,49 & Baik \\
Gambar mempermudah memahami materi & 3,48 & Baik \\
Kemudahan materi dalam bahan ajar untuk dipahami & 3,47 & Baik \\
Kejelasan petunjuk kegiatan & 3,43 & Baik \\
Kemampuan bahan ajar untuk digunakan mandiri & 3,63 & Baik \\
Keterkaitan materi dalam kehidupan sehari-hari & 3,59 & Baik \\
\multicolumn{1}{c}{ Rata-rata } & $\mathbf{3 , 5 1}$ & Baik \\
\hline
\end{tabular}

Berdasarkan Tabel 5, didapatkan hasil respon siswa terhadap bahan ajar PhysCCTM adalah Baik. Disimpulkan bahwa bahan ajar PhysCCTM Baik untuk digunakan dalam pembelajaran fisika.

\subsubsection{Efektivitas Produk PhysCCTM}

Data dari pretest dan posttest hasil HOTS siswa dapat dilihat pada Tabel 6 berikut Tabel 6. Hasil Pretest dan Posttest

\begin{tabular}{llll}
\hline Komponen & Kelas & Mean & $\begin{array}{l}\text { Standar } \\
\text { Deviasi }\end{array}$ \\
\hline Pretest & Eksperimen & 43,73 & 9,96 \\
& Kontrol & 46,02 & 8,01 \\
\hline Posttest & Eksperimen & 82,12 & 10,10 \\
& Kontrol & 77,17 & 8,81 \\
\hline
\end{tabular}

Tabel 6 menunjukkan besarnya perbedaan skor rata-rata antara kelas ekperimen dan kontrol yaitu 43,73 dan 46,02, dengan standar deviasi yang diperoleh masing-masing kelas adalah 9,96 dan 8,01 untuk pretest. Disisi lain, untuk hasil posttest didapatkan skor rata-rata antara kelas ekperimen dan kontrol adalah 82,12 dan 77,17, dengan standar deviasi yang diperoleh 10,10 dan 8,81. Nilai dari standar deviasi menunjukkan peningkatan HOTS siswa setelah melakukan pretest dan posttest.

Analisis efektivitas produk PhysCCTM menggunakan GLM (General Linear Model) Mixed Design. Sebelum melakukan uji efektivitas, terlebih dahulu dilakukan uji prasyarat, yaitu uji normalitas dan homogenitas. Uji normalitas mmenggunakan Shapiro-Wilk dan uji homogenitas menggunakan Lavene's Test dengan $\alpha=0,05$. Adapun hasil dari uji normalitas data disajikan pada Tabel 7 berikut

Tabel 7. Hasil Uji Normalitas Data

\begin{tabular}{ccccc}
\hline \multirow{2}{*}{ Komponen } & \multirow{2}{*}{ Kelas } & \multicolumn{3}{c}{ Shapiro-Wilk } \\
\cline { 3 - 5 } & & Statistik & $d f$ & Sign. \\
\hline \multirow{2}{*}{ Pretest } & Eksperimen & 0,949 & 37 & 0,093 \\
& Kontrol & 0,953 & 37 & 0,112 \\
\hline \multirow{2}{*}{ Posttest } & Eksperimen & 0,969 & 37 & 0,379 \\
& Kontrol & 0,953 & 37 & 0,122 \\
\hline
\end{tabular}


Tabel 7 di atas menunjukkan bahwa nilai signifikansi yang didapat lebih dari $\alpha=0,05$. Sehingga dapat disimpulkan bahwa data yang didapatkan berasal dari distribusi yang normal. Hasil dari homogenitas data berdasarkan Lavene's test dapat dilihat pada Tabel 8 berikut

Tabel 8. Hasil Uji Homogenitas Data

\begin{tabular}{ccc}
\hline Komponen & $\begin{array}{c}\text { Lavene's } \\
\text { Statistik }\end{array}$ & Sign. \\
\hline Pretest & 1,962 & 0,166 \\
Posttest & 3,263 & 0,075 \\
\hline
\end{tabular}

Berdasarkan Tabel 8, nilai dari signifikansi pada kedua komponen lebih besar dari $\alpha=$ 0,05 , sehingga dapat disimpulkan data pada kedua komponen bersifat homogen.

Setelah data diuji normalitas dan homogenitasnya, langkah selanjutnya adalah mengukur efektivitasnya. Tujuan dari GLM Mixed Design adalah untuk melihat hipotesis, 1) hubungan/ interaksi antara pretest dan posttest dengan kelas experimen dan kelas kontrol, 2) peningkatan skor yang signifikansi dari pretest dan posttest dengan kelas eksperimen dan kelas kontrol.

Hubungan interaksi antara pretest dan postets dengan kelas eksperimen dan kelas kontrol dapat dilihat dalam hasil output data dari Test of Within-Subject Effect pada Anava mixed design yang dapat dilihat pada Tabel 10 berikutTabel 10. Test of Within Effect

\begin{tabular}{cccccccc}
\hline Source & $\begin{array}{c}\text { Type III } \\
\text { Sum of } \\
\text { Squares }\end{array}$ & df & $\begin{array}{c}\text { Mean } \\
\text { Squares }\end{array}$ & F & Sign & $\begin{array}{c}\text { Partial } \\
\text { eta } \\
\text { Squared }\end{array}$ \\
\hline Time*Group & $\begin{array}{c}\text { Greenhouse- } \\
\text { Geisser }\end{array}$ & 838,68 & 1,00 & 838,68 & $12,, 934$ & 0,000 & 0,093 \\
\hline
\end{tabular}

Tabel 11. Pairwise Comparisons

\begin{tabular}{|c|c|c|c|c|c|c|c|}
\hline \multirow{2}{*}{ Group } & \multirow{2}{*}{ (I) Time } & \multirow{2}{*}{ (J) Time } & \multirow{2}{*}{$\begin{array}{c}\text { Mean } \\
\text { Difference } \\
\quad(\mathrm{I}-\mathrm{J})\end{array}$} & \multirow{2}{*}{$\begin{array}{l}\text { Std. } \\
\text { Error }\end{array}$} & \multirow[t]{2}{*}{ Sig. ${ }^{a}$} & \multicolumn{2}{|c|}{$\begin{array}{l}\text { 95\% Confidence } \\
\text { Interval for } \\
\text { Difference }^{\mathrm{a}}\end{array}$} \\
\hline & & & & & & $\begin{array}{l}\text { Lower } \\
\text { Bound }\end{array}$ & $\begin{array}{l}\text { Upper } \\
\text { Bound }\end{array}$ \\
\hline \multirow[t]{2}{*}{ Eksperimen } & Pretest & Posttest & $-38.396^{*}$ & 1.391 & .000 & -41.149 & -35.642 \\
\hline & Posttes & Pretest & $38.396^{*}$ & 1.391 & .000 & 35.642 & 41.149 \\
\hline \multirow[t]{2}{*}{ Kontrol } & Pretest & Posttest & $-31.148^{*}$ & 1.458 & .000 & -34.033 & -28.262 \\
\hline & Posttest & Pretets & $31.148^{*}$ & 1.458 & .000 & 28.262 & 34.033 \\
\hline
\end{tabular}

Berdasarkan Tabel 11, nilai dari signifikansi kurang dari 0,05, ini menandakan adanya interaksi antara waktu (pretest-postest) dan kelas (ekperimen dan kelas kontrol). Hubungan ini menunjukkan perubahan nilai pretest dan nilai posttest untuk kemampuan HOTS siswa pada kedua kelas yang berbeda secara signifikan. Untuk signifikansi perubahan hasil pretest dan posttest dari kelas eksperimen dan kontrol dapat dilihat pada output dari hasil data Pairwise Comparissons pada GLM Mixed Design yang ada pada Tabel 11.

Efektivitas dari penggunaan PhysCCTM pada kelas eksperimen dan kelas kontrol dapat dilihat dari output Multivariate Test pada Partial Eta Squared yang dapat dilihat pada Tabel 12 berikut 
Tabel 12. Multivarite Test

\begin{tabular}{cccccccc}
\hline Group & Value & F & $\begin{array}{c}\text { Hypothesis } \\
\text { df }\end{array}$ & Error df & Sig. & $\begin{array}{c}\text { Partial } \\
\text { Eta } \\
\text { Squared }\end{array}$ \\
\hline Eksperimen & $\begin{array}{c}\text { Hotelling's } \\
\text { trace }\end{array}$ & 6,044 & $7.616 \mathrm{E}^{\mathrm{a}}$ & 1.000 & 126.000 & .000 & .858 \\
\hline
\end{tabular}

Tabel 12 menunjukkan bahwa efektivitas dari PhysCCTM untuk meningkatkan Higher Order Thinking Skill (HOTS) adalah 0,858 atau 85,8\%. Interaksi antara kelas eksperimen dan kelas kontrol dapat dilihat pada grafik output dari Estimated Marginal Means pada GLM Mixed Design output yang dapat dilihat pada Gambar 2 berikut

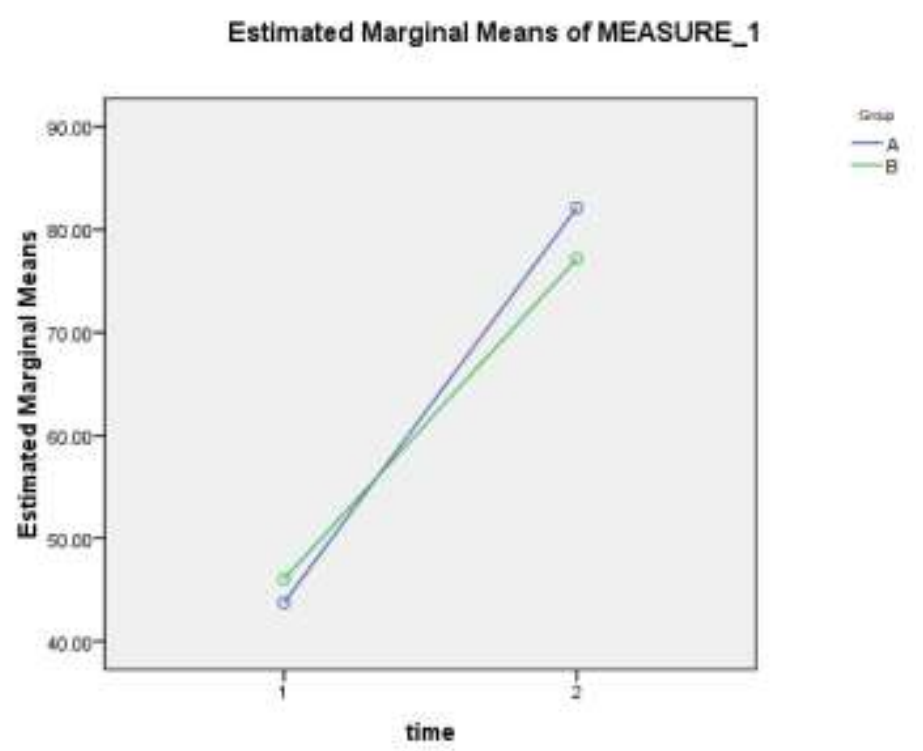

Gambar 2. Grafik Output dari Estimated Marginal Means pada GLM Mixed Model

Gambar 2 di atas menunjukkan bahwa peningkatan kemampuan HOTS siswa pada kelas eksperimen lebih tinggi dari pada peningkatan kemampuan HOTS siswa pada kelas kontrol.

\section{SIMPULAN DAN SARAN}

\subsection{Simpulan}

1) Penelitian ini menghasilkan produk bahan ajar PhysCCTM pada materi Teori Kinetik Gas untuk meningkatkan HOTS siswa SMA yang telah memenuhi kriteria kelayakan berdasarkan ahli, praktisi dan respon siswa.

2) Bahan ajar PhysCCTM efektif untuk meningkatkan HOTS siswa yang dapat dilihat dari Partial Eta Squared dengan nilai yang diperoleh sebesar 0,858 atau 85,8\%.

\subsection{Saran}

Berdasarkan penelitian yang telah dilakukan adapun saran yang dapat diberikan yaitu

1) Bahan ajar PhysCCTM pada materi teori kinetic gas dapat digunakan untuk meningkatkan HOTS yang disusun secara comprehensive dan kontekstual. 
2) Guru dan siswa dapat memanfaatkan bahan ajar ini sebagai referensi dalam proses belajar mengajar di kelas, Karena bahan ajar ini telah teruji kelayakannya oleh ahli, praktisi, dan respon siswa

3) Bahan ajar PhysCCTM dapat digunakan untuk belajar mandiri oleh siswa .

\section{DAFTAR PUSTAKA}

Balitbang, Kemdikbud. (2014). Laporan Hasil Ujian Nasional tahun 2014.

www.Litbang.kemdikbud.go.id

Borich. (1994). Observation skill for effective teaching. New York: Mcmillian.

Brookhart, S. M. (2010). How To Assess Higher Order Thinking Skill in Your Classroom. Alexandria: ASCD

Limbach, B \& Waugh, W. (2010). Developing Higher Level Thinking [Versi elektronik]. Journal of Instructional Pedagogies, 5, 1-9

PISA. (2015). PISA 2015 Results In Focus. OECD. Dapat diakses di www.OECD.org/pisa/pisa-2015-results-in-focus.pdf.

Ramos, J.L.S., Bretel B.D., \& Brenda B.V. (2013). Higher Order Thinking Skills and Academic Performance in Physics Of Collage: A Regression Analysis. International Journal of Innovative Interdiciplinary Research, 4, 48-60.

Stevens, J. P. (2009). Applied multivariate statistics for the social sciences. New York: Taylor \& Francis Group.

Thiagarajan, S., Semmel, D. S., \& Semmel, M. I. (1974). Instructional Development For Training Teachers of Exceptional Children. Indiana: Eric Inc.

TIMSS. (2011). International Result in Science. International Study Center, Lynch School of Education. Boston Collage. http://nces.ed.gov/timss/results11.asp. 